This is a postprint version of the following published document:

Salom, C., Prolongo, M. G., Masegosa, R. M., Baselga, J. \&. Guemes, A. (1992). Rubber-modified epoxy resins cured with piperidine. European Polymer Journal, 28 (9), pp. 1135-1139.

DOI: 10.1016/0014-3057(92)90068-D

(C) Pergamon Press, 1992

(C) Elsevier

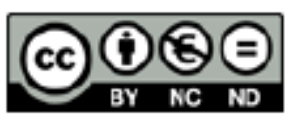

This work is licensed under a Creative Commons Attribution-NonCommercialNoDerivatives 4.0 International License. 


\title{
RUBBER-MODIFIED EPOXY RESINS CURED WITH PIPERIDINE
}

\author{
C. Salom,${ }^{1}$ M. G. Prolongo,${ }^{1 *}$ R. M. Masegosa, ${ }^{2}$ J. BaSelga $^{1}$ and A. Guemes ${ }^{1}$ \\ 'Departamento de Materiales y Producción Aerospacial, Escuela Técnica Superior de \\ Ingenieros Aeronáuticos, Universidad Politecnica, 28040 Madrid, Spain \\ ${ }^{2}$ Departamento de Tecnologias Especiales Aplicadas a la Aeronáutica, Escuela Universitaria de Ingeniería Técnica \\ Aeronáutica, Universidad Politecnica, 28040 Madrid, Spain
}

\begin{abstract}
Glass transition temperatures $\left(T_{\mathrm{g}}\right)$ of epoxy resins, diglycidyl ether of bisphenol-A cured with piperidine, have been measured by differential scanning calorimetry and dynamic mechanical thermal analysis in order to follow the curing process. Optimum cure conditions have been established as $3 \% \mathrm{PP}$ at $120^{\circ} \mathrm{C}$. T s of the neat epoxy system and those modified with 5 and $16 \%$ of a carboxyl-terminated reactive rubber copolymer of butadiene and acrylonitrile (CTBN) have been determined as a function of the cure time. Addition of $5 \%$ of CTBN does not modify the process, but the higher CTBN content accelerates the initial stage. $T_{\mathrm{g}} \mathrm{s}$ after long cure times $\left(T_{\mathrm{g}}^{\infty}\right)$ are lower for the modified systems than for the neat, showing that CTBN is not fully segregated. The amounts of CTBN dissolved in the epoxy crosslinked network have been estimated.
\end{abstract}

\section{INTRODUCTION}

Crosslinked epoxies are known as thermosets with high glass transition temperature but they are brittle materials. Addition of carboxyl-terminated reactive rubber copolymer of butadiene and acrylonitrile (CTBN) improves the toughness of cured epoxy resins [1-3]. During cure, phase separation of the rubber occurs as a result of the increase in molecular weight, which reduces the compatibility of the rubber with the epoxy system. Thus, a microstructure of rubbery particles in a matrix of cured epoxy is obtained $[4,5]$.

There have been many studies on epoxy resins using amines as curing agents [1-8]. The diglycidyl ether of bisphenol-A (DGEBA) cured with piperidine (PP) and modified with CTBN has been used as a model for studying microstructure and fracture behaviour $[4,9,10]$. This system has two peculiar features: piperidine causes an athermal cure of the epoxy resin and the cure time with this amine is relatively long (several tens of hours). Even though several conditions for cure have been tried, using different temperatures and times of curing at constant PP content $[4,10]$, the temperature and cure times were selected in such a way that they do not allow a systematic discussion of the effects of both variables on the curing of the epoxy. In effect, the low temperature cures provided the highest $T_{\mathrm{g}}$ for the samples. To explain these results, it was suggested that the behaviour results from different time/temperature paths or because of volatilization of PP.

In an attempt to understand more fully the behaviour of the system of epoxy with PP, the aim of this work is to study the cure process of two rubber
$16 \%$ CTBN) and an unmodified neat system as a control. A preliminary report has been published [11]. Because of the athermal character of the cure process, it was monitored by determining glass transition temperatures $\left(T_{\mathrm{g}}\right)$ as a function of the cure time. The first part of the work involves assessing the optimum cure conditions with respect to temperature and content of PP. In the second part, $T_{g} \mathrm{~S}$ and degrees of cure for unmodified and modified systems have been determined as a function of cure time; the relative amounts of dissolved and phase-separated rubber have been calculated from the depression of $T_{\mathrm{g}}$ of the fully cured system.

\section{EXPERIMENTAL PROCEDURES}

\section{Materials}

The epoxy resin was DGEBA manufactured by CIBA under the trade name Araldite F (CY205) with an epoxy equivalent weight of $190 \mathrm{~g} \cdot$ equiv $^{-1}$. Its structural formula is shown in Fig. 1. The curing agent was PP (Merck) (b.p. $105^{\circ}$ ), a secondary amine catalyst that promotes the homopolymerization of epoxy (see Fig. 1). The rubber modifier was CTBN $1300 \times 8$ (B. F. Goodrich); it has an acrylonitrile content of $18 \%$ by wt, mol. wt 3600 , density $0.948 \mathrm{~g} \mathrm{~cm}^{-3}$ and $-\mathrm{COOH}$ equivalent weight $2000 \mathrm{~g} \cdot$ equiv $^{-1}$.

\section{Method}

The simple unmodified epoxy resin was degassed in a vacuum oven at $50^{\circ}$ for $30 \mathrm{~min}$; when it had cooled to below $30^{\circ}$, the piperidine was mixed in gently to avoid air trapping; the epoxy-piperidine mixture was then cured in an aluminium pan, according to the chosen cure conditions. Since the cure agent is relatively volatile, it was checked that no loss of mass occurred even at the highest cure temperature. 
<smiles>[X]CC(CC)(CC1CO1)Oc1ccc(C(C)(C)c2ccc(OCC(O)CC(C)(C)Oc3ccc(C(C)(C)c4ccc(OCC5COC5)cc4)cc3)cc2)cc1</smiles>

EPOXY RESIN

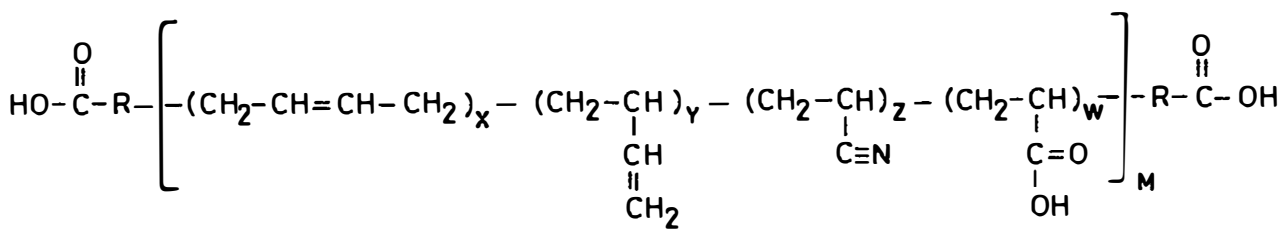

CTBN

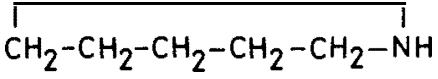

\section{PIPERIDINE}

Fig. 1. Structural formulae.

at $60^{\circ}$ until no air bubbles were detected. The addition of PP was made in the same way as for the unmodified system; the cure conditions for the modified system were $120^{\circ}$ and $3 \%$ of piperidine. In all cases, the reaction was stopped at various times by cooling to room temperature.

\section{Techniques}

Differential scanning calorimetry (DSC). DSC measurements were carried out with a Perkin-Elmer DSC-4 over the range $-50-170^{\circ}$. Measurements were made under $\mathrm{N}_{2}$ at a heating rate of $20 \% \mathrm{~min}$ with samples of about $10 \mathrm{mg}$. Subambient measurements were made using liquid $\mathrm{N}_{2}$ to cool the DSC cell. Indium was used for calibration. $T_{\mathrm{g}}$ was taken as the midpoint of the specific heat change.

The increase of $T_{\mathrm{g}}$ with reaction time at a given temperature was followed by using several DSC aluminium pans filled with reactants placed in an oven at the selected cure temperature. Pans were removed from the oven at intervals and scanned in the DSC. Two runs were performed for each sample, giving equal $T_{\mathrm{g}}$ values without observing any exothermal peak of reaction heat, according to the athermal character of the cure with piperidine.

Dynamic mechanical thermal analysis (DMTA). Dynamic mechanical analysis was also used to determine $T_{\mathrm{g}}$ of the thermoset epoxy-matrix polymers, using a DMTA Polymer Lab. Instrument. For specimen preparation, the degassed mixture of epoxy with PP was poured into a mould and cured in an air oven to prepare a casting of dimensions $25 \times 8 \times 1 \mathrm{~mm}$. The mechanical study was done at $30 \mathrm{~Hz}$ and a heating rate of $3^{\circ} / \mathrm{min}$. Transition temperatures were identified by the temperature of maxima in $\tan \delta$ during a temperature scan $\left(20-150^{\circ}\right)$. All the experiments were performed in $\mathrm{N}_{2}$ at mosphere.

\section{RESULTS AND DISCUSSION}

\section{Unmodified epoxy system}

We attempted first to fix the optimum cure conditions, i.e. weight percent of cure agent (PP) and cure temperature for which the extent of reaction reaches a maximum. We selected 120 and $160^{\circ}$ as cure temperatures according to preliminary studies reported by Kinlonch et al. [10], and carried out several cure experiments with different weight percent of PP $\left(W_{\mathrm{p}}\right)$, in order to clarify the effects of temperature/time on the cure reaction.

Figures 2(a) and (b) show $T_{g}$ of the epoxy vs PP content determined by DSC and DMTA, for curing conditions $120^{\circ} / 16 \mathrm{hr}$ and $120^{\circ} / 72 \mathrm{hr}$ respectively. As expected, there is a difference (about $15^{\circ}$ ) between $T_{\mathrm{g}}$ values from the two techniques, nevertheless the PP dependences are very similar, so we refer to results for the DSC values. Figure 2(c) shows the $T_{\mathrm{g}}$ values under cure conditions $160^{\circ} / 6 \mathrm{hr}$. The variation of $T_{8}$ with PP content exhibits in all cases (Fig. 2) a maximum. When time is increased from $16 \mathrm{hr}$ to $72 \mathrm{hr}$ at $120^{\circ}, T_{\mathrm{g}}$ increases for the same PP content and the maximum observed is displaced from 5 to $3 \%$ PP. At $160^{\circ}$, the maximum is reached at $8 \%$ of PP with $T_{\mathrm{g}}$ lower than the corresponding value for $120^{\circ}$. These results can be explained by noting that the $T_{\mathrm{g}}$ can be considered as a measure of the extent of reaction. The displacement of the maximum at $120^{\circ}$ towards a lower PP content for a longer cure time, indicates that the concentration of PP does not help the overall cure process, and increasing PP content improves the extent of the reaction only in the first stages (short cure times). On the other hand as can be seen in Fig. 2(c), increase of temperature does not have a great effect on the extent of reaction at short cure time $(6 \mathrm{hr})$; therefore in this system, cure time has a greater effect than temperature. Our results agree with those already reported $[4,10]$, and explain why lower $T_{g}$ s and higher molecular mass between crosslinks have been found for the highest cure temperature at short cure times. 


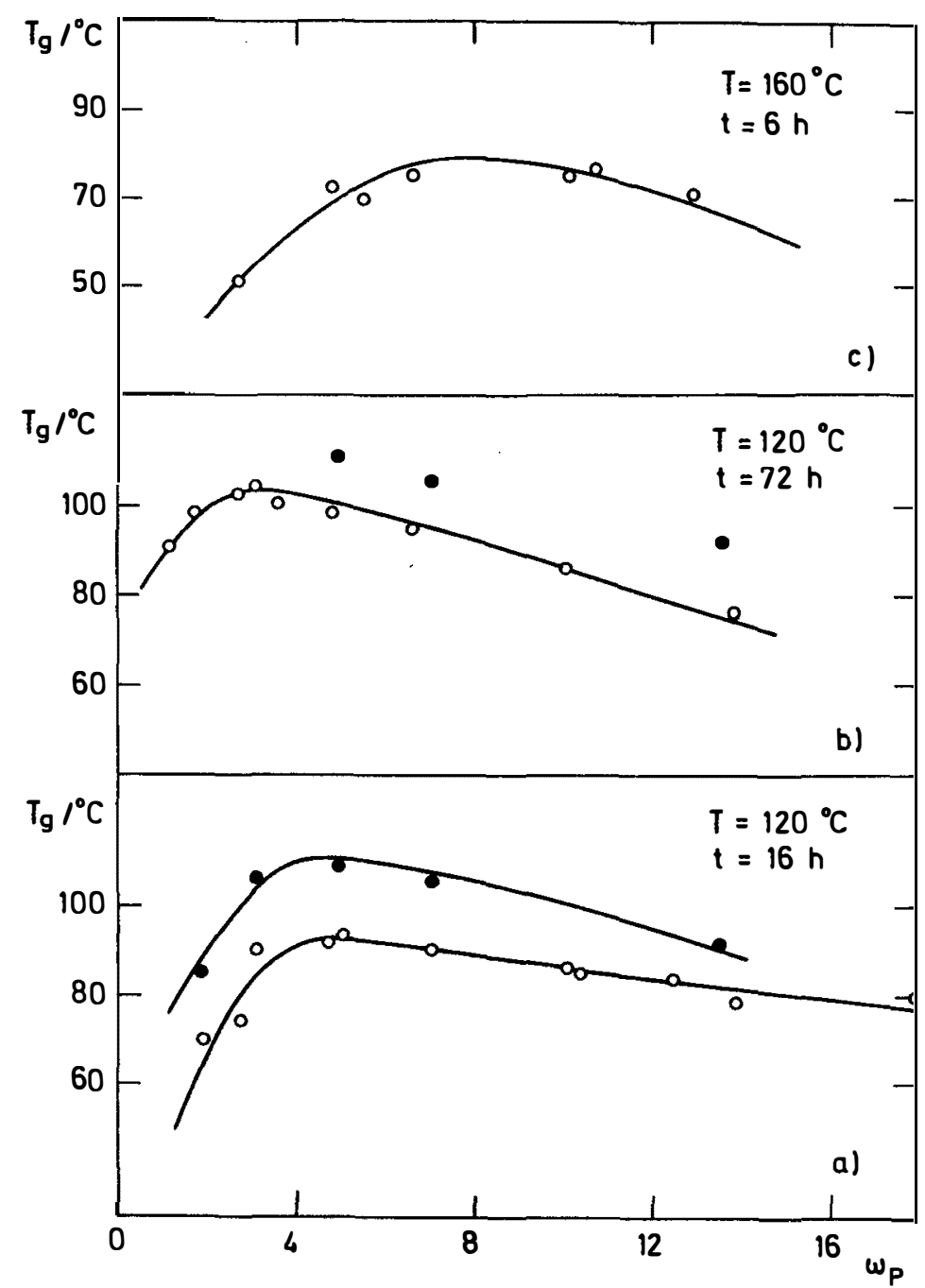

Fig. 2. Glass transition temperatures for the neat epoxy system vs weight percent of PP, for different cure conditions. Data from DSC (O) and from DMTA (O).

In all cases, the decrease of $T_{\mathrm{g}}$ when the PP content is higher than that corresponding to the maxima seems to indicate a plastifying effect of PP. This effect is shown also on the moduli of several epoxy systems (Table 1). The table includes the average molecular mass between crosslinks $\left(\bar{M}_{\mathrm{c}}\right)$ calculated from the expression $[12,13]$.

$$
\log \frac{E^{\prime}}{3}=6.0+\frac{293 \cdot d}{M_{c}}
$$

where $E^{\prime}$ is the rubbery equilibrium modulus of the epoxy determined at $160^{\circ}$ (well above $T_{g}$ of the epoxy) and $1 \mathrm{~Hz}, d$ is the density of the epoxy $\left(1.18 \mathrm{~g} \cdot \mathrm{cm}^{-3}\right)$.

Table 1. $T_{\mathrm{g}}, E^{\prime}$ and $\bar{M}_{\mathrm{c}}$ values (from DMTA) for the neat system cured at $120^{\circ} / 290 \mathrm{hr}$

\begin{tabular}{cccc}
\hline$W_{\mathrm{p}}$ & $T_{\mathrm{g}}\left({ }^{\circ} \mathrm{C}\right)$ & $E^{\prime} \cdot 10^{-7}(\mathrm{~Pa})$ & $\bar{M}_{\mathrm{c}}(\mathrm{g} / \mathrm{mol})$ \\
\hline 1.76 & 110 & 1.3 & 540 \\
5.01 & 104 & 1.04 & 640 \\
7.09 & 99.5 & 0.698 & 940 \\
\hline
\end{tabular}

These $\bar{M}_{\mathrm{c}}$ values must be taken as "apparent" values because the decrease in $\bar{M}_{\mathrm{c}}$ with PP content may not be due to a decrease in the crosslinking degree but to a plastifying effect of PP.

As a consequence of these results, curing conditions of $120^{\circ}$ and $3 \%$ PP content have been fixed for a second stage, i.e. the study of the influence of cure time in the cure of epoxy system. Figure 3 shows $T_{8}$ at several cure times up to $150 \mathrm{hr}$. Cure times of $290 \mathrm{hr}$ and $3000 \mathrm{hr}$, not shown in Fig. 3 both gave $T_{\mathrm{g}}=112^{\circ}$; therefore this value corresponds to complete curing of the epoxy resin. Even though the process takes a long time, a very high extent of the reaction has been reached at about $20 \mathrm{hr}$. Note that the cure temperature is slightly higher than the $T_{\mathrm{g}}$ obtained at the end of reaction, so one would not expect a noticeable influence of any process controlled by diffusion.

On the other hand, although $T_{\mathrm{g}} \mathrm{s}$ are not expected to vary linearly with the cure degree $(\alpha)$ over the entire range of cure, a linear relationship between $T_{\mathrm{g}}(t)$ and $\alpha(t)$ can be applied at degrees of cure that are not very high $\left(T_{g} \mathrm{~s} \mathrm{ca} 50^{\circ}\right.$ below cure temperature) 


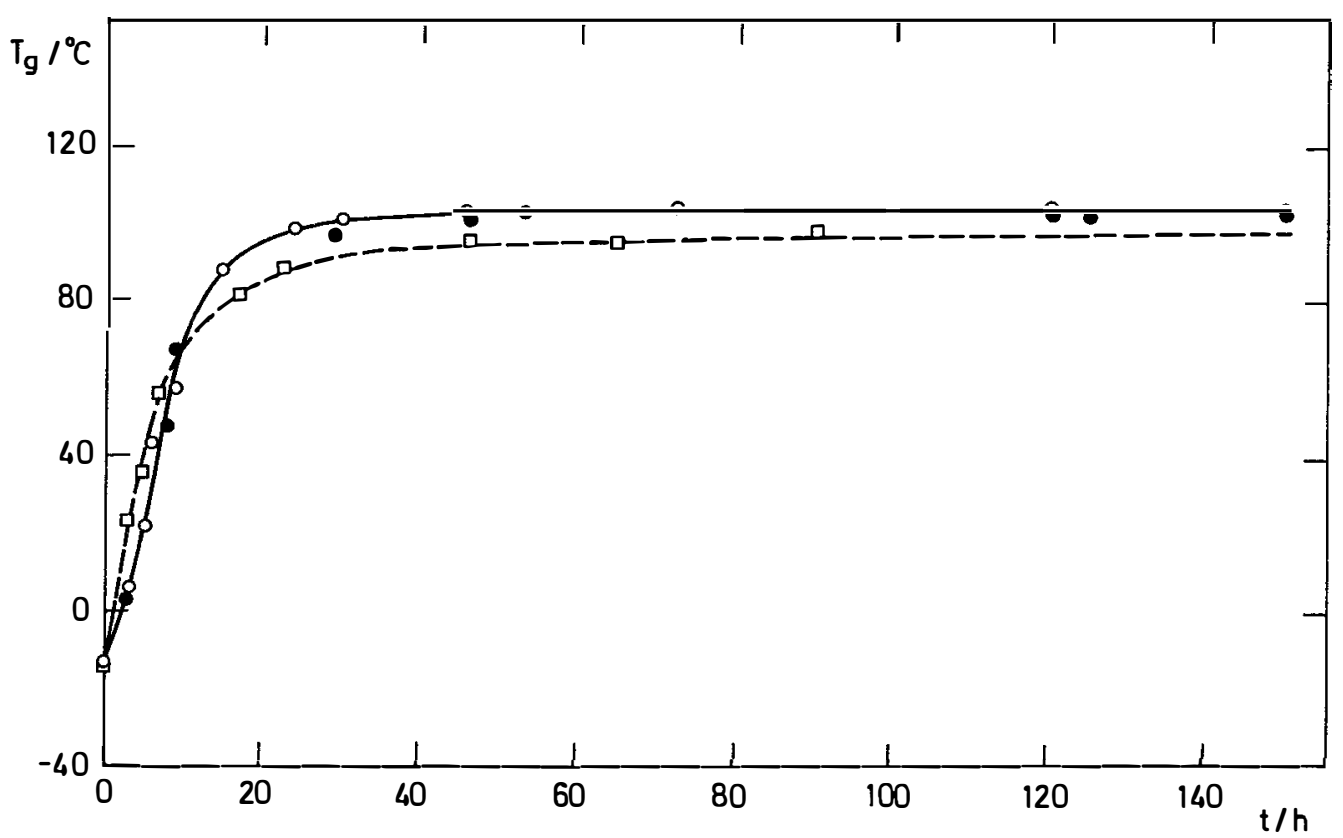

Fig. 3. Glass transition temperature vs cure time for the neat epoxy system $(O)$, modified with $5 \%$ CTBN (๑) and with $16 \%$ CTBN ( $\square)$.

$[15,16]$. With this hypothesis, we can calculate $\alpha(t)$ from the following expression:

$$
\alpha(t)=\frac{T_{\mathrm{g}}(t)-T_{\mathrm{g}}^{0}}{T_{\mathrm{g}}^{\infty}-T_{\mathrm{g}}^{0}}
$$

where $T_{\mathrm{g}}^{0}$ is the value of $T_{\mathrm{g}}$ at zero time $\left(T_{\mathrm{g}}^{0}=-14^{\circ}\right)$. The results are shown in Table 2 .

\section{Rubber-modified-system}

Two rubber-modified epoxy-systems $(5$ and $16 \%$ CTBN) were selected in order to compare their behaviour with that of an unmodified epoxysystem.

Figure 3 shows that, for $5 \% \mathrm{CTBN}$, there is no significant difference in the $T_{\mathrm{g}}$ vs time behaviour with the neat epoxy system; only a slight decrease of $T_{\mathrm{g}}$ can be seen at very long cure times, resulting in $T_{\mathrm{g}}=108^{\circ}$ ( $4^{\circ}$ lower than $T_{\mathrm{g}}$ of the unmodified system).

However for $16 \%$ CTBN, the cure of the system varies not only for long cure times but also for short times. As can be seen in Fig. 3, for cure times $<10 \mathrm{hr}$, the $T_{\mathrm{g}}$ values are higher than the corresponding values for a neat system (for example at $5 \mathrm{hr}$ the difference between $T_{\mathrm{g}} \mathrm{s}$ is $14^{\circ}$ ); it means that a large CTBN content causes increase of the reaction rate in the initial stages, so we can estimate how quickly the reaction develops by comparing the degrees of cure

Table 2. Degree of cure, $\alpha$, at short cure times

\begin{tabular}{ccc}
\hline & \multicolumn{2}{c}{ Degree of cure, $\alpha$} \\
\cline { 2 - 3 } Cure time (hr) & $\begin{array}{c}\text { Unmodified } \\
\text { system }\end{array}$ & $16 \%$ CTBN \\
\hline 3 & 0.16 & 0.32 \\
5 & 0.29 & 0.43 \\
6 & 0.35 & $0.53^{*}$ \\
7 & $0.46^{*}$ & 0.60 \\
9 & 0.57 & $0.68^{*}$ \\
\hline
\end{tabular}

*Interpolated values. for modified and unmodified epoxy systems; this comparison is reported in Table 2 . This accelerating effect of the rubber on the reaction might be valid for several epoxy systems; it has been detected also in another case [8] using as cure agent a secondary diamine and as rubber an epoxy-terminated butadiene/acrylonitrile statistical copolymer.

Moreover the $T_{\mathrm{g}}$ for cured rubber-modified epoxy system is $102^{\circ}\left(10^{\circ}\right.$ lower than $T_{\mathrm{g}}$ of the neat system). The decrease of $T_{\mathrm{g}}$ is considered to arise from incomplete phase separation, i.e. the dissolved-rubber plasticizes the epoxy matrix. From these values, we have determined the amount of dissolved rubber using the Fox equation (17) relating $T_{\mathrm{g}}$ of a mixture $\left(T_{\mathrm{g}}\right)$ with those of the pure components, $T_{\mathrm{g}_{1}}$ and $T_{\mathrm{g}_{2}}$.

$$
\frac{1}{T_{\mathrm{g}}}=\frac{W_{1}}{T_{\mathrm{g}_{1}}}+\frac{W_{2}}{T_{\mathrm{g}_{2}}}
$$

where $T_{\mathrm{g}}$ refers to the rubber modified epoxy matrix; $T_{g_{1}}$ to the neat system and $T_{g_{2}}$ to the unreacted rubber $(220 \mathrm{~K}) ; W_{1}$ and $W_{2}$ are the weight fractions of the epoxy and the rubber in the homogeneous matrix. The values of $W_{2}$ obtained are 1.4 and $3.7 \%$ for $5 \%$ CTBN and $16 \%$ CTBN respectively.

Finally for short cure times around $10 \mathrm{hr}$, the $T_{\mathrm{g}} \mathrm{s}$ for the unmodified and rubber modified systems are the same. This result agrees with those of Kinloch et al. [10], who obtained equivalent $T_{\mathrm{g}} \mathrm{s}$ for both systems indicating virtually complete phase separation. This fact must be considered as apparent because the $T_{\mathrm{g}}$ values have been taken when the cure reaction is not complete and, as we have shown, at long cure times there is some dissolved rubber plasticizing the epoxy matrix.

Acknowledgements - The authors thank Dr A. J. Kinloch for advice in this investigation. We are grateful to CIBAGEIGY for kindly providing the samples. Financial support 
by the Comisión de Investigación Científica y Tećnica is acknowledged (89/0435).

\section{REFERENCES}

1. J. N. Sultan and F. J. McGarry. Polym. Engng Sci. 13, 29 (1973).

2. A. J. Kinloch. In Strucural Adhesives: Developments in Resins and Primers (edited by A. J. Kinloch). Elsevier Applied Science, London (1986).

3. W. D. Bascom and D. L. Hunston. In Rubber-Toughened Plastics (edited by C. K. Riew), Chap. 6. American Chemical Society, Washington D.C. (1989).

4. L. T. Manzione, J. K. Gillham and C. A. McPherson. J. appl. Polym. Sci. 26, 889 (1981).

5. L. T. Manzione, J. K. Gillham and C. A. McPherson. J. appl. Polym. Sci. 26, 907 (1981).

6. L. C. Chan, J. K. Gillham, A. J. Kinloch and S. J. Shaw. In Rubber-Modified Thermoset Resins (edited by C. K. Riew and J. K. Gillham), Advances in Chemistry 208, Chaps 15 and 16. American Chemical Society. Washington D.C. (1984).

7. Epoxy Resins. Chemistry and Technology (edited by C. A. May). New York (1988).

8. D. Verchere, H. Sautereau, J. P. Pascault, S. M. Moschiar, C. C. Riccardi and R. J. J. Williams. J. appl. Polym. Sci. 41, 467 (1990).

9. A. J. Kinloch and D. L. Hunston. J. Mater. Sci. Lett. 6, 131 (1987).

10. A. J. Kinloch, C. A. Finch and S. Hashemi. Polym. Commun. 28, 332 (1987).

11. Abstracts of the National Symposium on Polymers, Valencia, Spain, 26-29 June, p. 204 (1989) and 2427 June, p. 275 (1991).

12. L. E. Nielsen. J. macromolec. Sci. C3, 69 (1969).

13. D. C. Timm, A. J. Ayodeji and R. F. Floral. Br. Polym. J. 17, 227 (1985).

14. J. M. Barton. Makromolek. Chem. Macromolec. Symp. 7, 27 (1987).

15. T. H. Hou and J. M. Bai, SAMPE Jl 24(6), 43 (1988).

16. J. B. Enns and J. K. Gillham. J. appl. Polym. Sci. 28, 2567 (1983).

17. T. G. Fox. Bull. Am. Phys. Soc. 1, 123 (1956). 